plug even better than the child's breech, provoke uterine activity, and give the opportunity either for spontaneous delivory by the head or by the forceps, either of which gives a much better chance of saving the child without compromising the safety of the mother. The combined method of turning comes in admirably in some cases, but it is only an application of this proceeding. It cannot be regarded as constituting by itself the rational treatment of placenta prævia. I am, Sirs, yours truly,

Harley-street, June 6th, 1887. ROBERT BARNES.

\section{"A SUGGESTED IMPROVEMENT IN ETHER INHALERS."}

To the Editors of THE LANCET.

SIRs,-Under the above heading, Mr. Rickard W. Lloyd, in an interesting communication in your issue of May 28th calls attention to a possible danger of Clover's ether inhaler, and he suggests that the anæsthetiser should possess and use a number of indiarubber bags to minimise the risks of transmitting disease from one patient to another.

Mr. Lloyd, as, I believe, all who administer ether will allow, has put his tinger upon the weak part of Clover's inhaler, which is the bag. Unless the apparatus is in constant use the bag gets out of order. In hospital practice, and in the practice of surgeons who have much operating, it is tolerably easy with care to maintain the bag in good order; but even then holes will mysteriously and unaccountably appear in it. But the general practitioner, who has to let his apparatus lie on the shelf for an unknown length of time, too often finds, when he requires it on an emergency, that the bag has stuck together, and can only be opened up at the cost of tearing, or has already several perforations in it, and then sticking plaster or other tinkering expedients have to be used to render the apparatus temporarily workable. Regarding the carbonic poisoning which the bag of Clover's apparatus causes in greater or less degree, I refrain from expressing an opinion, as I have heard it condemned on the one hand as a danger, and extolled on the other as a virtue, by competent authorities. I would, however, ask those who approve this carbonic acid poisoning if, supposing they were about to inhale ether, they would give instructions to the anæsthetiser to allow their own blood to become carbonised, or whether they would not, on the contrary, prefer that their blood should be as free as possible from this noxious gas, and consequently the action of the right side of the heart be impeded as little as possible? Deaths from ether are unfortunately not unknown, and it behoves us to adopt every measure to render its administration safe as well as effective. For some time I have been making trials with an apparatus which Messrs. Mayer, Meltzer, and Co. have constructed to my order, which, whilst doing away altogether with the bag, retains all the useful features of Clover's apparatus. The patient never re-breathes expired air, and the danger pointed out by $\mathrm{Mr}$. Lloyd cannot therefore occur. My trials and experiments are not yet complete, but $I$ hope that the firm mentioned may soon be able to offer to the profession an efficient and handy inhaler which will surmount Mr. Lloyd's difficulties oven more satisfactorily than his own suggestions do.

I remain, Sirs, your obedient servant,

Norman Porrits,

May 31st, 1887. Hon. Surgeon, Huddersfield Infirmary

\section{THE HOVE INFECTIOUS HOSPITAL.} To the Editors of THE LANCET.

SIRs,-As it is your practice in all disputed cases to give facilities for "the other side" to obtain a hearing, I trust shat you will permit me, as one of the laymen whom you condemn in your article of May 28th for directing public attention to the alleged defects at the Hove Sanatorium or Infectious Hospital, to offer a few remarks by way of explanation. In the first place, these "laymen," whilst claiming no great or extensive sanitary knowledge, have had considerable experience in hospitals and hospital management. General Shute, C.B., both in the Crimea and in India, learnt much practical knowledge in field and other hospitals, and, without being an "expert," now possesses valuable experience on the subject. I am no novice in hospital management, having for many years been interested and concerned in hospital government. At the present time I am one of the house committes of the largest lospital in London. Therefore, feeling ourselves qualified to form an independent opinion, we ventured to criticise the report of the local medical officer, who stated that "all the requisites of an institution of the kind were all that can be desired." I have no intention of giving in detail the deficiencies to which we ventured to direct attention; it will be sufficient for me to say on this occasion thet we complained of defects in the arrangements (owing to the peculiar site on the fowns), of defects in the condition of the building, and of deficiencies as regards certain sanitary appliances. We are confident that thes defects would be admitted by competent and independent sanitary authorities. We are anxious only for the truth as to the facts and for efficiency as to the hospital, and we desire competent inspection, and fully believe that we shall thereby obtain confirmation of our criticisms. Te have a duty to our constituents which we are anxious to fulfil. A large sum of public money has been expended on this hospital; our constituents are rated for its repayment. They deserve an efficient hospital for their outlay, and, conscientiously believing that at the present time the hospital is not in a satisfactory condition, we ventured to raise our voices against the optimistic report of the medical offeer, feeling sure that the public attention thus aroused would ensure the removal of the defects of which we had complained. In conclusion, I may add that the cost of remedying these defects would only amount to an inconsiderable sum of money. Under the circumstances, I trust that you will regard our conduct as deserving of praise and not of blame, and that you will assist us and not add to our difficulties in rendering this hospital thoroughly efficient.
Brighton, June, 1887. I am, Sirs, yours truly.

* * We took no exception to a mere endeavour to remedy such defects as may exist in this hospital, but we do not admit that some of the conditions which were alleged to indicate defects are faults at all. Mr. Henriques brought for ward statements calculated to damage the hospital in the minds of the general public, and thus to hinder the very object for which it was erected. He is also reported to have objected to its ventilation, to have said that "the arrangements...... were the very reverse of what such an institution should possess"...... and "were as bad as they could be"; and he spoke of its "fatal objections." We deny the accuracy of such statements, and, in answer to them, we would quote the following authorities, who have at least equal knowledge with Mr. Henriques as to what are the requirements of an infectious hospital. Dr. Ewart, chairman of the Brighton Sanitary Committee, says: "The ventilation is excellent"; and he adds that "with proper care and mangement......your building...... will prove a great benefit to the town." Dr. Kelly, medical officer of health to West Kent, says: "On the whole, the building seems to have been carefully planned, and to be well adapted for use as an infectious hospital." Such statements alone suffice to show how unwise was the wholesale condemnation of the hospital which was made public last month.-ED. L.

\section{THE VALUE OF DRUGS.}

\section{To the Editors of THE LANCET.}

SrRs,--The remark of Sir William Gull at the recent meeting of the Medical Council has elicited considerable correspondence on the value of drugs in the treatment of disease. I have no doubt he never intended that his remark should be taken literally, but only that it should be a strong blow at the system of empirical treatment pursued principally by dispensing chemists over the country. Every medical practitioner must have noticed how much faith the uneducated place in a bottle of medicine, and must also bo aware how some dispensing chemists and all quacks pander to this taste. There is in this way many a shilling wasted in medicine that might have been well spent in a good beef steak or coal for the fire. Medicine is seldom the most important part in the treatment of disease, and it is of the utmost importance for us at all times toimpress this upon our 